\title{
Effect of Folate Supplementation on Inflammatory Markers in Individuals Susceptible to Depression: A Systematic Review
}

\author{
Helen Barnett ${ }^{1}$, Nathan M. D’Cunha ${ }^{1,2}$, Ekavi N. Georgousopoulou'1,2,3, Jane Kellett ${ }^{1,2}$, Duane D. \\ Mellor ${ }^{1,2,4}$, Andrew J. McKune ${ }^{1,2,5}$ and Nenad Naumovski ${ }^{1,2,6^{*}}$ \\ ${ }^{1}$ Faculty Health, University of Canberra, Kirinari Street, Bruce, Canberra, ACT, 2617, Australia; ${ }^{2}$ Collaborative Research in Bioactives \\ and Biomarkers (CRIBB) Group, Kirinari Street, Bruce, Canberra, ACT, 2617, Australia; ${ }^{3}$ Department of Nutrition-Dietetics, School of \\ Health and Education, Harokopio University, Athens, 17671, Greece; ${ }^{4}$ School of Life Sciences, Coventry University, Coventry, CV1 2DS, \\ UK; ${ }^{5}$ University of Canberra Research Institute for Sport and Exercise (UCRISE), University of Canberra, Bruce, Canberra, ACT, 2617, \\ Australia; ${ }^{6}$ University of Canberra Health Research Institute (UCHRI), University of Canberra, Bruce, Canberra, ACT, 2617, Australia
}

\begin{abstract}
Folate has been proposed to be an efficacious treatment strategy for depression. The mandatory fortification of flour with synthetic folic acid (FA) in over 80 countries has yielded improvements in folate intake; however, depression is still a considerable public health concern. While there are established benefits of FA fortification in reducing risk of neural tube defects, the implications regarding depression are unclear, especially in individuals with certain genetic polymorphisms. Therefore, a systematic review was conducted to examine the effects of folate to treat depression. Following PRISMA guidelines, a systematic review was conducted of electronic databases (PUBMED, Scopus, CINAHL, and Cochrane Library) to identify human clinical trials examining the effects of folate (including FA) supplementation in the management or prevention of depression, the impact on inflammatory markers and if genetic polymorphisms were considered. Ten trials met the inclusion criteria. Seven trials examined effects of either adjunctive FA or L-methylfolate (L-MTHF) supplementation with antidepressants in the management of depression and three examined effects of FA supplementation alone for prevention of depression. No benefit of FA was found compared to placebo (all, $p>0.05$ ). The single L-MTHF trial that explored the interplay of genetic polymorphisms and methylation status found benefit in the Hamilton depression rating scale from adjunctive treatment with $15 \mathrm{mg} /$ day of L-MTHF compared with placebo $(-6.8 \pm 7.2 \mathrm{vs} .-3.7 \pm 6.5 ; p=0.017)$ and improvement with L-MTHF for most genetic markers. Currently, there is no evidence to support FA supplementation for the management or prevention of depression. More research is required to determine the efficacy of L-MTHF and folinic acid in certain clinical populations.
\end{abstract}

Keywords: Folic acid; Homocysteine; Depression; Epigenomics.

Abbreviations: 4-HNE, 4-hydroxy-2-nonenal; 5-HIAA, 5-hydroxyindoleacetic acid; 5-MTHF, 5-methyltetrahydrofolate; BDI, Beck depression inventory; BMI, body mass index; CI, confidence interval; CVD, cardiovascular disease; DHF, dihydrofolate; DSM-IV, Diagnostic and Statistical Manual of Mental Disorders IV; FA, folic acid; Hcy, homocysteine; HDRS, Hamilton depression rating scale; hs-CRP, highsensitivity C-reactive protein; IL, interleukin; L-MTHF, L-methylfolate; MINI, mini international neuropsychiatric interview; MTHFR, methylenetetrahydrofolate reductase; NS, not specified; NTD, neural tube defects; OR, odds ratio; RCF, red blood cell folate; SAH, S-adenosylhomocysteine; SAMe, S-adenosylmethionine; THF, tetrahydrofolate; TNF- $\alpha$, tumor necrosis factor-alpha.

Received: July 31, 2017; Revised: October 31, 2017; Accepted: November 14, 2017 ${ }^{*}$ Correspondence to: Nenad Naumovski, Room 1C130; Faculty of Health; Locked Bag 1; University of Canberra, Canberra, ACT, 2601, Australia. Tel: +61 262068719 , Fax: +61 2 62015999, E-mail: nenad.naumovski@canberra.edu.au

How to cite this article: Barnett H, D'Cunha NM, Georgousopoulou EN, Kellett J, Mellor DD, McKune AJ, Naumovski N. Effect of Folate Supplementation on Inflammatory Markers in Individuals Susceptible to Depression: A Systematic Review. Exploratory Research and Hypothesis in Medicine 2017;2(4):86-100. doi: 10.14218/ERHM.2017.00025.

\section{Introduction}

The identification of folate as a key nutrient in the prevention of human disease, and particularly neural tube defects (NTD) in utero, ${ }^{1}$ has led to public health interventions based on mandatory folic acid (FA) fortification. These measures have been deemed necessary to reduce the incidence of NTD; and, while FA supplementation has been found to be successful in reducing NTD, ${ }^{1,2}$ there remains controversy surrounding the safety of mandatory fortification. ${ }^{3-5}$ Mandatory fortification exposes the whole population to a synthetic form of folate, rather than just the target population, while consumption of foods containing natural forms of folate is decreasing. ${ }^{6-8}$

Over 80 countries have implemented a mandatory FA fortification policy. The intake of folate in countries with mandatory fortification is often higher than the recommended ranges, calling into question whether mandatory fortification is warranted in other countries. ${ }^{9}$ In countries with mandatory fortification, FA is avail- 
able as either a supplement ( $400 \mu \mathrm{g}$ to $4 \mathrm{mg}$ /day recommended in pregnancy, depending on medical history) or through the fortification of flour and cereal products. ${ }^{10}$ Fortification levels vary worldwide, with a FA level of $140 \mu \mathrm{g} / 100 \mathrm{~g}$ implemented in the United States in $1998^{5}$ and $200-300 \mu \mathrm{g} / 100 \mathrm{~g}$ in Australia as of 2009. ${ }^{11}$ Although increased folate reduces plasma homocysteine (Hcy), ${ }^{6}$ excessive FA consumption from fortified foods may impair intracellular folate metabolism and play a role in epigenetic changes linked to increased inflammation and non-communicable diseases including depression. ${ }^{12-16}$

\section{Types of folate}

Folate was first discovered in 1931 by Wills, as a substance in yeast extract, and it was found to be effective in the treatment of pregnancy-related anemia. ${ }^{17}$ Currently, there are multiple structural forms of the vitamin that have been identified ('synthetic' and 'natural' forms), as well as a result of metabolic processes, which makes understanding the role of folate in human health and disease incredibly complex. ${ }^{17}$ Due to humans not being able to synthesize folate, it must be obtained from dietary sources, such as leafy green vegetables, with the main forms in food being 5-methyltetrahydrofolate (5-MTHF) and formyltetrahydrofolate. ${ }^{18}$

The main structural differences between natural and synthetic forms of folate are the oxidation state, the number of conjugated glutamic acid moieties and the type of one-carbon substituents at the N5 and N10 positions. ${ }^{17}$ Dietary folate is predominantly 5-MTHF, which is the biologically active form of the vitamin but may also exist as formyltetrahydrofolate or in the oxidized form 5-methyl-5,6-dihydrofolate. The latter is rapidly degraded; however, the secretion of ascorbic acid into the gastric lumen appears to be a critical mechanism to reduce it back to the more stable 5-MTHF; therefore, increasing the bioavailability of food folates. ${ }^{17}$ Accordingly, 5-MTHF is demethylated to form tetrahydrofolate (THF) by methionine synthase, so that it can be used for the synthesis of nucleotides.

In contrast, synthetic FA exists as the fully oxidized pteroylmonoglutamic acid, ${ }^{19}$ which is chemically more stable and cheaper to produce than most other forms of folate. ${ }^{4}$ Like 5-MTHF, FA is also metabolized to THF; however, it is via a much 'slower' twostep process catalyzed by the enzyme dihydrofolate reductase and producing the intermediate dihydrofolate (DHF) ${ }^{20}$ Consequently, human ability to absorb and process FA to biologically active forms of folate is saturated at daily intakes of between 266-400 $\mu$ g. ${ }^{21,22}$ Folinic acid is another form of folate supplement available and is commonly used after methotrexate treatment for various types of cancers. ${ }^{17}$

\section{Roles of folate in health}

Folate, as 5-MTHF, is required for the synthesis of the DNA nucleotide thymidine from the RNA nucleotide uracil and is, thus, vital for the stability of DNA. Therefore, folate deficiency is associated with misincorporation of uracil into DNA and DNA strand breakages. ${ }^{23}$ As DNA is incorporated into all cells, folate is especially important for rapidly dividing cells, such as red blood cells, and is consequently associated with anemia. ${ }^{24}$ Similarly, folate plays a conflicting role in cancer development, depending on the stage of cancer. Adequate folate levels prevent the expression of oncogenes and promote DNA stability before cancer initiation; however, after cancer cells have become established, folate can stimulate cell division and growth. ${ }^{25-28}$
Folate also provides a methyl group for the conversion of Hcy back to methionine, which leads on to the production of S-adenosylmethionine (SAMe). The reduction of Hcy also appears to be a vital aspect of this cycle, as elevated Hcy has been associated with disorders ranging from cardiovascular disease (CVD) ${ }^{29,30}$ to mental health disorders. ${ }^{31-35}$ The importance to CVD has primarily been investigated due to the role of FA in lowering Hcy, and also due to its ability to enhance nitric oxide production, thereby reducing the endothelial dysfunction associated with CVD..$^{36,37}$ Similarly, folate plays a role in the recycling of tetrahydrobiopterin, a cofactor involved in the synthesis of the neurotransmitters dopamine, serotonin and noradrenaline. ${ }^{32,34}$

\section{Folate and mental health}

Folate was first observed to be associated with perturbations in mental health when Victor Herbert consumed a diet deficient in folate in $1962 .{ }^{38}$ In 1978 , Boetz et al. ${ }^{39}$ observed that both under- and over-supplementation of FA resulted in low brain serotonin levels in rats, indicating that folate was involved in the synthesis of neurotransmitters. Epidemiological studies have suggested that low folate status is associated with depression, ${ }^{40,41}$ severity of depression ${ }^{40,42,43}$ and response to antidepressant treatment, ${ }^{41,43,44}$ though the exact mechanisms of action are still not understood.

To date, there is focus on: the relevance of folate in recycling tetrahydrobiopterin, a cofactor in the synthesis of the neurotransmitters; ${ }^{32,34}$ the function of folate as a methyl donor and the role it plays in the production of SAMe; ${ }^{32,34}$ the importance of SAMe in the methylation of neurotransmitters; ${ }^{32,45}$ and, the accumulation of both Hcy and its precursor metabolite S-adenosylhomocysteine (SAH), which has been shown to be neurotoxic due to its inhibition of monoamine metabolism. ${ }^{46-48}$ Similarly, genome-wide association studies have shown a link between the methylenetetrahydrofolate reductase (MTHFR) C677T mutation and certain mental health disorders, such as depression and schizophrenia. ${ }^{49-51}$

Many trials have been conducted to understand the role that folate plays in human neurochemistry. ${ }^{31,39,52-55}$ The function of folate as a methyl donor has led to a focus on the inflammatory marker Hcy, and whether lowering of this amino acid has a beneficial effect on depressive symptoms. While folate is vital for neurotransmitter production and mental health, it has become increasingly questioned whether FA is the best form of folate, ${ }^{4,20,56,57}$ and even if it may result in detrimental effects in some individuals which could be due to one or more of the many potential genetic polymorphisms within the folate pathway. ${ }^{58-61}$ Importantly, there is a need to consider whether folate biochemistry works similarly in different tissues. As the brain is a post-mitotic tissue, it does not synthesize nucleotides, and therefore the role of folate in the central nervous system is different. However, the ability to measure biomarkers accurately in the brain is challenging due to the invasive nature of such testing.

Therefore, the aim of this literature review is to examine human clinical trials to determine what type of folate supplementation have been used, what inflammatory markers have been measured, whether genetic polymorphisms have been explored and their effects, and measures of depressive symptoms. As there are concerns being expressed over the safety of FA supplementation and fortification, it appears timely to examine the evidence surrounding FA supplementation in the treatment of depression. In addition, this review will attempt to examine whether there are other mechanisms involved which have not yet been explored. 


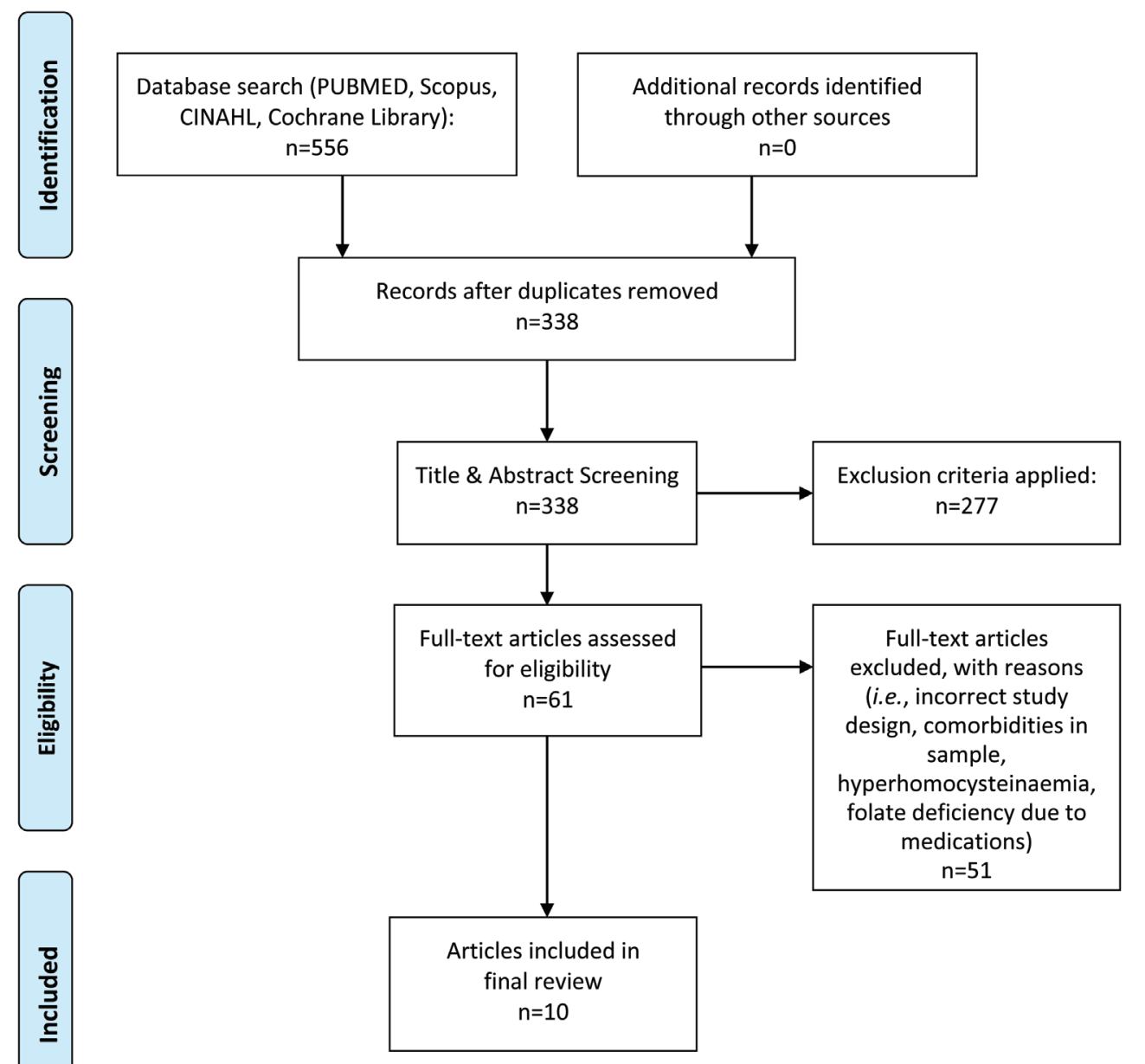

Fig. 1. PRISMA flow diagram.

\section{Methods}

A systematic review of published literature was performed to identify the evidence for folate supplementation to treat depression. A flow chart describing the study selection is presented in Figure 1.

\section{Search strategy}

Four electronic databases (PUBMED, Scopus, CINAHL and the Cochrane Library) were searched independently by two authors following the PRISMA 2009 guidelines, ${ }^{62}$ to identify human clinical trials examining the effects of folate (including FA) supplementation on the inflammatory markers Hcy, interleukins (ILs), tumor necrosis factor-alpha (TNF- $\alpha$ ) and high-sensitivity C-reactive protein (hs-CRP) in the treatment or prevention of depression. The database search used keyword terms related to the aim: "folic acid", "folate", "Folinic Acid", "methylfolate", "5-MTHF" in combination with "homocysteine", "interleukin*", "tumour necrosis factor alpha", "high sensitive C-reactive protein" AND "mental health" OR "depression". Two independent authors conducted the searches (H.B. and N.D.), and a manual search of the reference lists of review articles was also performed.

\section{Inclusion criteria}

The search included articles that measured depression as a primary or secondary outcome measure. We included studies if they measured Hcy or one and more inflammatory markers and if genetic polymorphisms were considered in the analysis. Only peerreviewed journal articles published in English were included. To assess the recent evidence regarding folate and depression, only randomized, placebo-controlled, human clinical trials conducted between the years of 1991 and 2017 were included. The year 1991 was selected due to the establishment of the role of FA in the prevention of NTD. ${ }^{1}$

\section{Exclusion criteria}

Observational studies were excluded due to considerable heterogeneity, difficulty in identifying the type of folate consumed, confounding due to socioeconomic factors and a reliance on selfreported data. During the search, two trials satisfied the inclusion criteria; ${ }^{63,64}$ however, they were excluded as the hyperhomocysteinemia that was being studied was secondary to, or a result of, the disease process, medication and/or treatment for the specific 
disease or condition. Consequently, the results of these trials were not generalizable to the wider population.

\section{Assessment of risk of bias}

The risk of bias was independently assessed by two reviewers (H.B. and N.D.) (Table $1^{38,65-73}$ ) using the criteria suggested in the Cochrane guidelines. ${ }^{74}$ The country and source of funding were also considered to illustrate if any bias may have been introduced into the study. Differences in opinion between reviewers were resolved through discussion until consensus was reached. When consensus could not be reached, co-authors (N.N. and E.G.) provided input until a final decision was agreed upon.

\section{Results}

\section{Description of studies}

In total, 338 studies were identified from the initial electronic database search. Of these, 61 titles were extracted for further analysis of their abstracts, with only 10 satisfying the inclusion criteria (Fig. 1). ${ }^{62}$ Six trials examined the effect of either FA or L-methylfolate (L-MTHF) as an adjunct to antidepressants in the treatment of depression, ${ }^{65-70}$ three examined the effect of FA supplementation on the prevention of depression as a standalone treatment, ${ }^{38,71,72}$ and one trial included participants who were all on antidepressant medication throughout the trial period (although the antidepressant was not part of the intervention) ${ }^{73}$ Nine of the trials measured Hcy, ${ }^{38,65-68,70-73}$ with one measuring hs-CRP and SAMe/ SAH ratio. ${ }^{69}$ No trials measured TNF- $\alpha$, IL or supplementation with folinic acid. Five trials considered the interaction between folate supplementation and genetic polymorphisms. Two studies analyzed single nucleotide polymorphisms in detail and presented their results, ${ }^{65,69}$ two made reference to the relevance of genetic polymorphisms in the folate pathway (mainly MTHFR) ${ }^{65,70}$ and one study excluded participants who were homozygous for the C677T polymorphism on the basis that it impairs folate status. ${ }^{38}$ A range of outcomes pertaining to depression was found in the included studies to assess depressive symptoms, such as the mini international neuropsychiatric interview (MINI) and the Beck depression inventory (BDI). The outcomes measures used in the included studies are briefly described in Supplementary Information 1.

For this review, the articles were categorized into either: 1. FA/ methylfolate as an adjunct in the treatment of depression (description of studies provided in Table $\left.2^{65-70,73}\right) ; 2$. FA as a standalone supplement in the prevention or treatment of depression (description of studies provided in Table $3^{38,71,72}$ ).

\section{Folate (FA and/or L-MTHF) as an adjunct to antidepressants in the treatment of depression}

Five included studies ${ }^{65-68,70}$ examined the effect of FA in enhancing the efficacy of antidepressants in the treatment of depression, while one study examined the use of L-MTHF as an adjunct to antidepressant treatment. ${ }^{69}$ The study by Loria-Kohen et al. ${ }^{73} \mathrm{did}$ not include the use of antidepressants in the study design or intervention. However, it was noted that all study participants were on either an antidepressant, anxiolytic or mood stabilizer. A summary of each of the studies is included in Table 1.
The duration of trials ranged from 6 weeks to 2 years, with sample sizes ranging from 27 to 900 participants. In the FA trials, almost two-thirds of the 1706 participants were female $(n=1060)$. In four of the studies, ${ }^{65,68-70}$ participants were recruited following diagnosis by the Diagnostic and Statistical Manual of Mental Disorders IV (DSM-IV) of Major Depression. ${ }^{75}$ Two studies examined adults with either depressive symptoms, ${ }^{67}$ or moderate to severe depression. ${ }^{66}$ Inclusion into the remaining study was based on a diagnosis of Restrictive Anorexia Nervosa or Eating Disorder Not Otherwise Specified..$^{73}$ In this study, a food frequency and "3-day food and drink record" also assessed low folate intake. All studies included measurements of either Hcy or hs-CRP. ${ }^{65-70,73}$ Levels of FA supplementation ranged from $0.4-10 \mathrm{mg} /$ day for FA and 15 $\mathrm{mg}$ /day for the L-MTHF trial.

Three studies observed a positive effect of adjunctive FA supplementation alongside antidepressants for the treatment of depression, ${ }^{68,70,73}$ while two studies observed no significant difference between placebo and intervention (all, $p>0.05) .{ }^{66,67}$ The trial by Almeida et $a l .{ }^{65}$ only observed a difference over 52 weeks of treatment, but not over 12 weeks.

The study by Coppen et al. ${ }^{68}$ found an overall positive effect of $500 \mu \mathrm{g} /$ day FA supplementation over 10 weeks alongside fluoxetine in the reduction of plasma Hcy concentration (placebo: 9.52 $\pm 3.22 \mu \mathrm{mol} / \mathrm{L}$; FA: $8.01 \pm 2.23 \mu \mathrm{mol} / \mathrm{L}, p<0.02$ ) and depressive scores (Hamilton depression rating scale (HDRS): $26.8 \pm 5.0$ decreasing to $8.1 \pm 5.4, p<0.05$ ). However, when the results were analyzed by sex, the beneficial effect of FA in the reduction of Hcy only extended to females (placebo: $8.56 \pm 2.34 \mu \mathrm{mol} / \mathrm{L}$ to $9.36 \pm$ $4.25 \mu \mathrm{mol} / \mathrm{L}, p<0.025 ; \mathrm{FA}: 9.46 \pm 3.69 \mu \mathrm{mol} / \mathrm{L}$ to $7.51 \pm 1.63$ $\mu \mathrm{mol} / \mathrm{L}$ ) and not males (placebo: $9.92 \pm 3.11 \mu \mathrm{mol} / \mathrm{L}$ to $10.21 \pm$ $3.88 \mu \mathrm{mol} / \mathrm{L}, p>0.05$; FA: $9.65 \pm 2.05 \mu \mathrm{mol} / \mathrm{L}$ to $9.01 \pm 2.90$ $\mu \mathrm{mol} / \mathrm{L}, p>0.05)$. The same sex relationship was also observed with respect to HDRS in females (placebo: $26.7 \pm 4.4$ to $11.4 \pm 6.9$; FA: $27.0 \pm 4.8$ to $6.8 \pm 4.1, p<0.05$ ) compared with males (placebo: $26.4 \pm 5.1$ to $9.7 \pm 7.9$; FA: $26.6 \pm 5.3$ to $10.9 \pm 6.8, p>0.05$ ). This was the also the only trial that represented its results by sex.

Also providing equivocal results was the trial by Almeida et $a l .,{ }^{65}$ which indicated that FA did not increase the efficacy of antidepressants at 12 weeks. For the criteria for major depression, the placebo group $(n=73)$ had a $78.1 \%$ improvement rate, while the FA group $(n=73)$ improved by $79.4 \%$ (between-group $p=$ $0.84)$. However, after 52 weeks, the FA group $(n=62)$ responded positively compared with the placebo group $(n=66)$. In this trial, intervention participants received $2 \mathrm{mg}$ /day FA, $0.5 \mathrm{mg}$ vitamin $\mathrm{B}_{12}$ and $25 \mathrm{mg}$ vitamin $\mathrm{B}_{6}$ alongside $20-40 \mathrm{mg}$ citalopram for 52 weeks. The primary outcome was remission of major depression (as defined by the DSM-IV-TR) and measured by the MINI. The Hcy, red blood cell folate (RCF) and serum vitamin $B_{12}$ were collected at baseline, and after 12, 26 and 52 weeks. FA supplementation resulted in an increased RCF $(+608.4 \mathrm{nmol} / \mathrm{L}, 95 \%$ confidence interval (CI): $487.8 \mathrm{nmol} / \mathrm{L}$ to $729.1 \mathrm{nmol} / \mathrm{L}$; $p$-value not specified (NS)), and a reduction in Hcy relative to baseline $(11.2 \mu \mathrm{mol} / \mathrm{L}$ to 9.1 $\mu \mathrm{mol} / \mathrm{L} ; p=\mathrm{NS})$. Positive effects of FA supplementation after 52 weeks included reduced rate of relapse amongst those who were no longer depressed by week 12, and greater odds of remission compared with placebo for those participants with a baseline Hcy $>10.4$ $\mu \mathrm{mol} / \mathrm{L}$ (odds ratio (OR): $3.47,95 \%$ CI: $1.22-9.84$ ), compared to those with Hcy $\leq 10.4 \mu \mathrm{mol} / \mathrm{L}$ (OR: $1.09,95 \% \mathrm{CI}: 0.32-3.75$ ).

The two remaining trials ${ }^{70,73}$ determined a positive effect of FA, using $10 \mathrm{mg} /$ day of FA supplementation with mostly female participants $(>85 \%)$. Interestingly, this dose is double the already high dose recommended for women with a high risk of NTD. ${ }^{76}$ In the study by Loria-Kohen et al., ${ }^{73} 24$ patients with an eating disorder, low dietary folate intake and depressive symptomatology (as assessed 


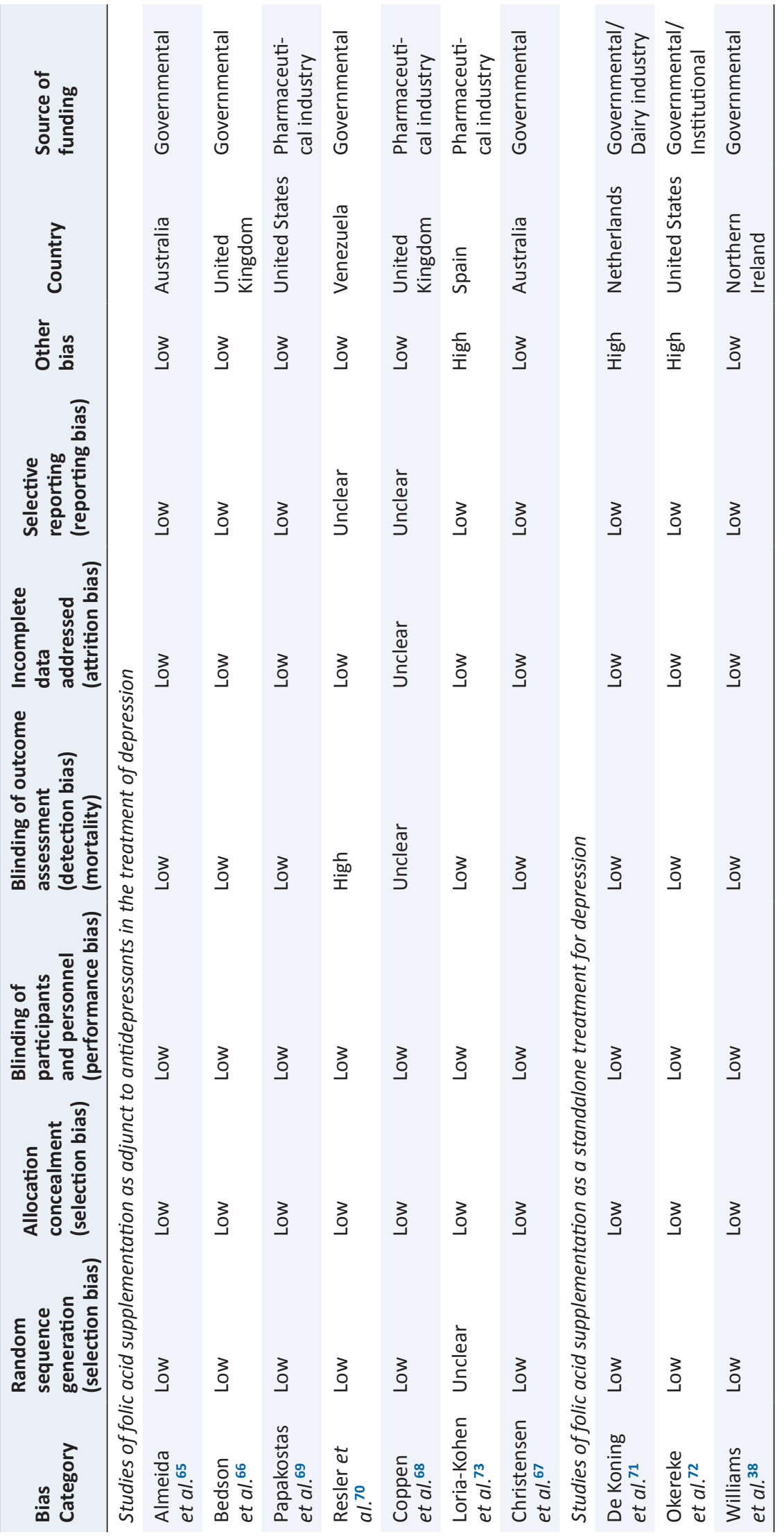




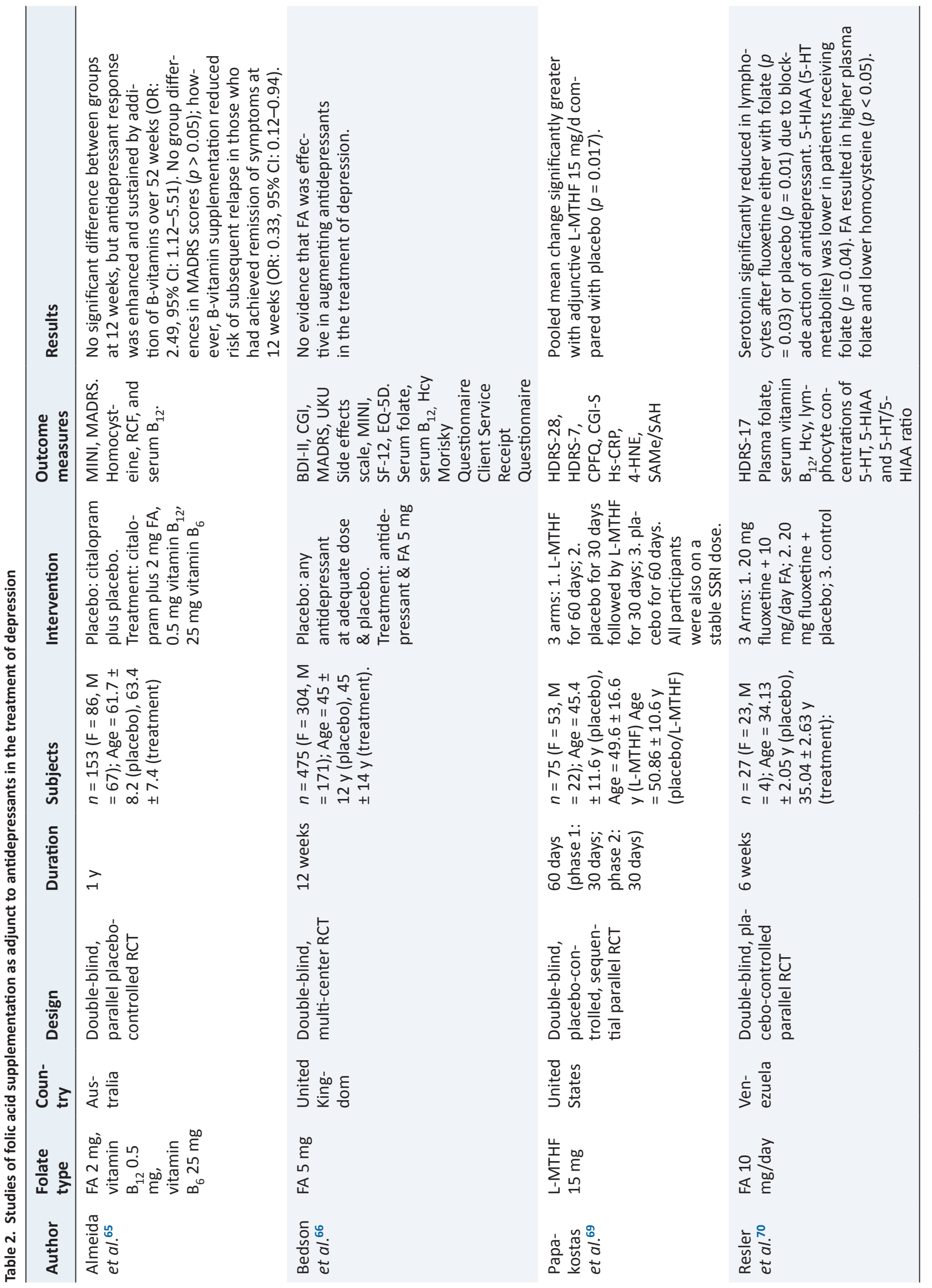



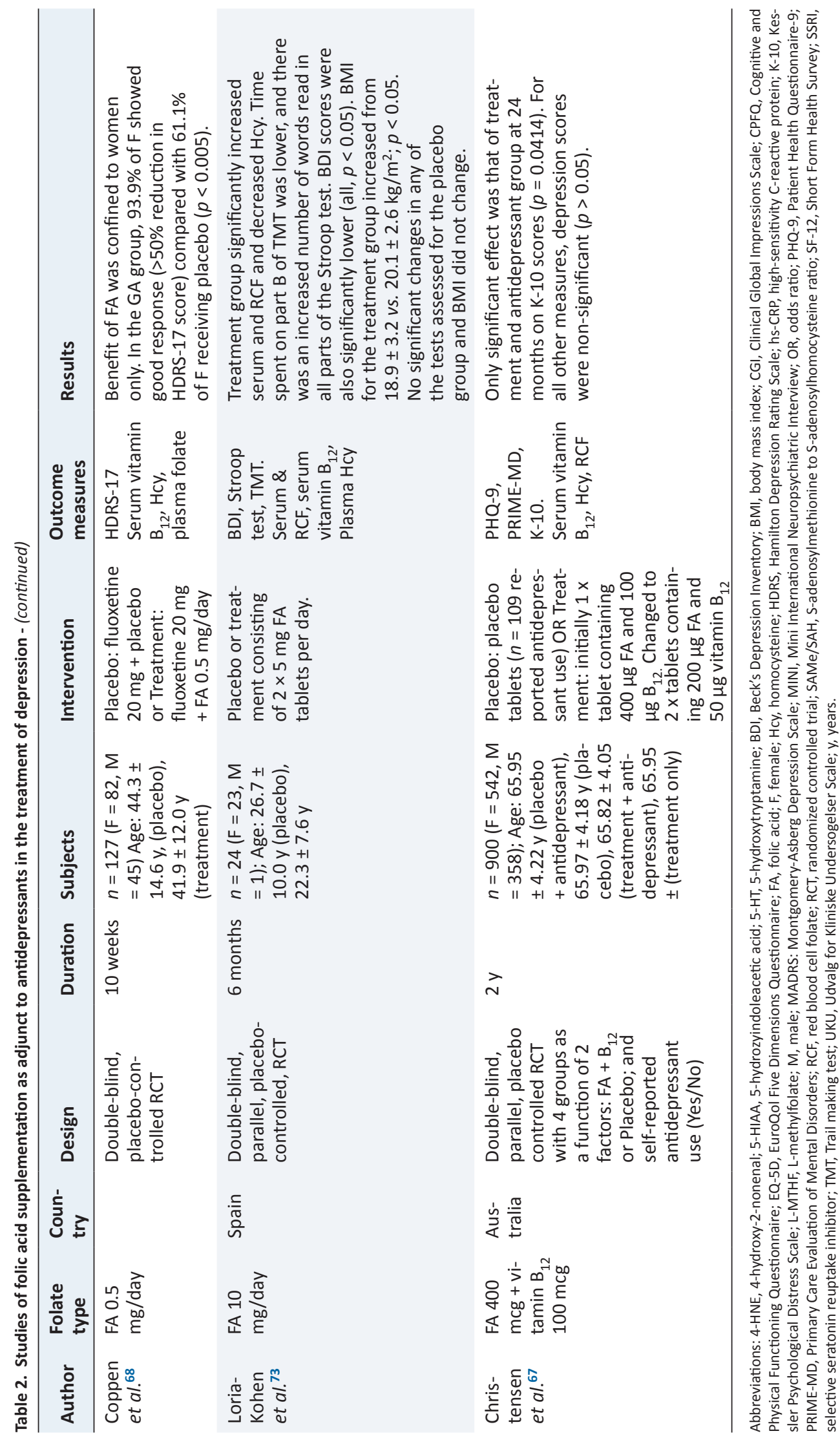


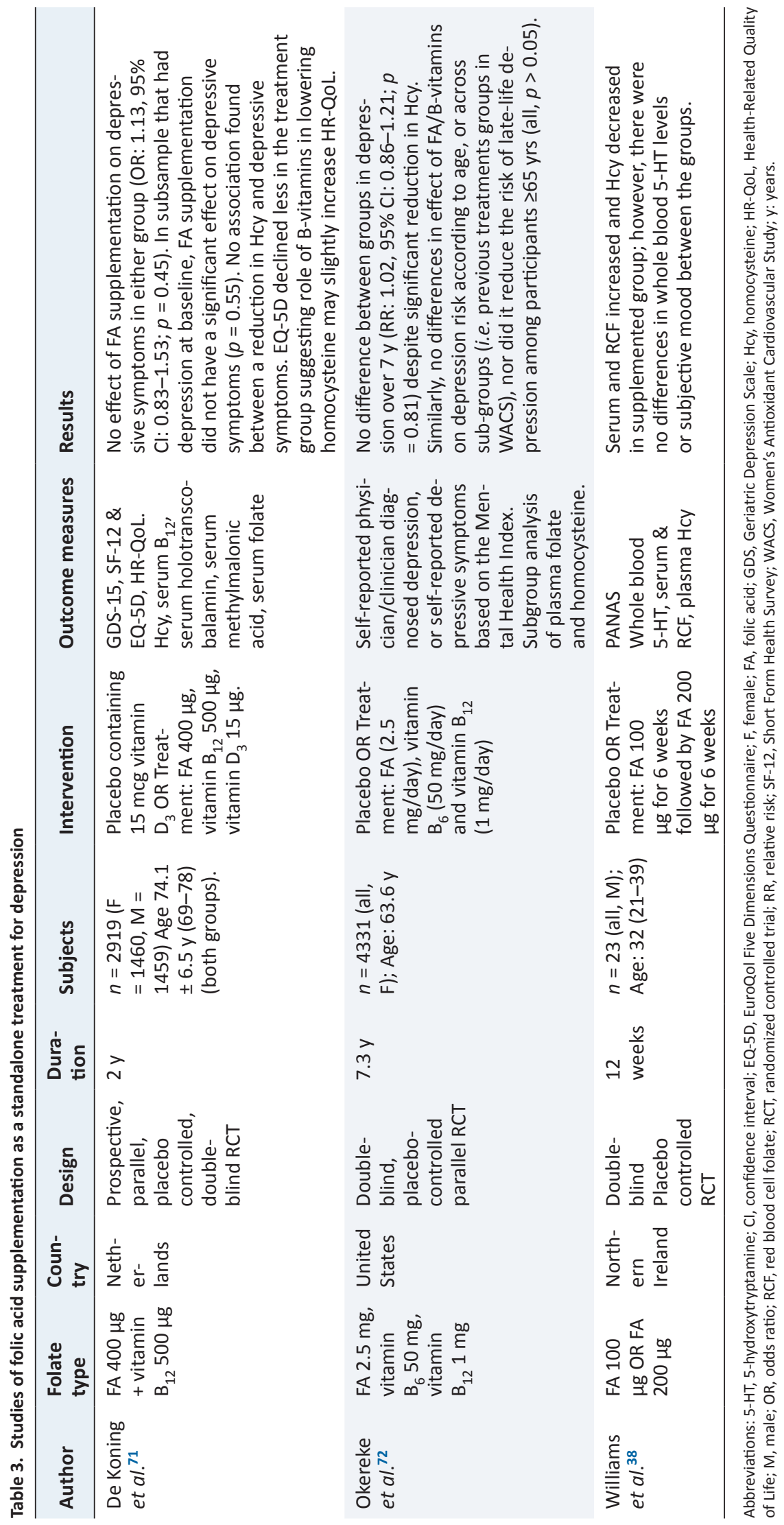


by the BDI) were randomized to either placebo or an intervention group supplementing with $10 \mathrm{mg} /$ day of FA for 6 months. Although antidepressant medication was not part of the intervention, $57.1 \%$ of the intervention group were taking antidepressants, $42.9 \%$ were taking anxiolytics, and $7 \%$ used mood stabilizers. In the placebo group, $70 \%$ were taking antidepressants, and $30 \%$ were taking anxiolytics. The main outcome measures were depressive symptomatology using the BDI and cognitive status using the Stroop and trail making tests. Data on serum folate, RCF, Hcy and serum vitamin $\mathrm{B}_{12}$ were also collected. Results indicated that RCF increased in the intervention group $(634.3 \pm 300.0 \mathrm{ng} / \mathrm{mL}$ to $1521.7 \pm 167.0 \mathrm{ng} / \mathrm{mL})$ compared with the placebo group $(844.4 \pm 285.4 \mathrm{ng} / \mathrm{mL}$ to $945.0 \pm 347.0$ $\mathrm{ng} / \mathrm{mL} ; p<0.0001)$. However, plasma Hcy concentrations in both groups decreased (placebo: $10.0 \pm 2.05 \mu \mathrm{mol} / \mathrm{L}$ to $8.0 \pm 1.8 \mu \mathrm{mol} / \mathrm{L}$; FA: $9.4 \pm 2.4 \mu \mathrm{mol} / \mathrm{L}$ to $7.5 \pm 1.7 \mu \mathrm{mol} / \mathrm{L})$. However, interestingly, only the reduction of Hcy in the supplemented group was reported to be significant $(p<0.01)$. Depression scores (as measured by the $\mathrm{BDI}$ ) decreased significantly in the FA (placebo: $17.3 \pm 12.1$ to 13.4 \pm 11.8 ; FA: $22.9 \pm 8.1$ to $15.2 \pm 9.9 ; p<0.05$ ).

The study by Resler et al. ${ }^{70}$ explored the effect of 6 weeks of $10 \mathrm{mg} /$ day FA supplementation in combination with fluoxetine on plasma Hcy and serotonin levels in lymphocytes. Primary outcome measures were a reduction in depressive symptoms measured by the HDRS-17, plasma folate, Hcy, serum vitamin $B_{12}$, serotonin and 5-hydroxyindoleacetic acid (5-HIAA). Results indicated that plasma folate increased significantly in the supplementation group $(9.22 \pm 1.97 \mathrm{nM}$ to $47.81 \pm 6.66 \mathrm{nM})$ compared with the placebo group $(9.10 \pm 1.66 \mathrm{nM}$ to $11.61 \pm 3.53 \mathrm{nM} ; p=0.0005)$, while plasma Hcy decreased significantly in the supplementation group from baseline $(9.49 \pm 0.7 \mathrm{pM}$ to $7.35 \pm 0.61 \mathrm{pM} ; p=0.02)$ (placebo group values were not reported). Mean HDRS scores were reduced from $22.50 \pm 0.98$ to $7.43 \pm 1.65$ in the FA group compared with $21.85 \pm 0.94$ to $11.43 \pm 1.31$ in the placebo group $(p=0.04)$. As expected, the serotonin concentration was reduced in lymphocytes due to the administration of fluoxetine and did not differ between the FA group $(p=0.03)$ or placebo group $(p=0.01)$. The main difference, however, was that in the FA group, 5-HIAA was significantly decreased $(p=0.04)$.

The trials by Bedson et al. ${ }^{66}$ and Christensen et al. ${ }^{67}$ reported no benefit from the adjunctive use of $5 \mathrm{mg}$ /day of FA for 12 weeks, and $0.4 \mathrm{mg} /$ day of FA with $0.1 \mathrm{mg} /$ day of vitamin $\mathrm{B}_{12}$ for 24 months, respectively. In the study by Bedson et al. ${ }^{66} 475$ participants were included initially (females, 304; males, 171) with the outcome measure, assessed by the BDI-II at 25 weeks, showing no evidence that FA was more effective than the placebo (OR: 1.09; 95\% CI: $0.75-1.59 ; p=0.65$ ). All other outcome measures showed no significant difference between FA and placebo $(p>0.05)$, except for the SF-12 mental component for the placebo group $(p=0.017)$. Similarly, the trial by Christensen et al. ${ }^{67}(n=900)$, in which 209 reported antidepressant use during follow-up, reported no clear evidence that FA enhanced the efficacy of antidepressants. Primary outcome measures were depressive symptoms measured by the PHQ-9 and PRIME-MD, and serum $\mathrm{B}_{12}$, RCF and Hcy. Results showed that there was no significant interaction between antidepressant use on depression as measured by PHQ-9 and K-10 $(p=0.868)$. However, there was a significant interaction effect between antidepressant use, FA and time, but only at 24 months $\left(\mathrm{F}_{4799.5}=2.50, p=0.041\right)$. The K-10 scores were lower in the FA with vitamin $\mathrm{B}_{12}$ group at 24 months than the placebo group $\left(\mathrm{t}_{789}=-2.24, p=0.025 ; 95 \%\right.$ CI: -3.68 to -0.24$)$. The FA supplementation increased RCF levels in the supplemented group from $573 \pm 266 \mathrm{nmol} / \mathrm{L}$ to $1019 \pm 410$ $\mathrm{nmol} / \mathrm{L}$ at 12 months and to $951 \pm 423 \mathrm{nmol} / \mathrm{L}$ at 24 months $\left(\mathrm{F}_{2729.0}\right.$ $=75.9, p<0.0001)$. This was in comparison to the placebo group that only had a slight increase from $557 \pm 277 \mathrm{nmol} / \mathrm{L}$ to $616 \pm 360$ $\mathrm{nmol} / \mathrm{L}$ at 12 months and $568 \pm 326 \mathrm{nmol} / \mathrm{L}$ at 24 months. The Hcy increased significantly $(p<0.0001)$ in the placebo group $(9.8 \pm 2.8$ $\mu \mathrm{mol} / \mathrm{L}$ to $11.6 \pm 2.7 \mu \mathrm{mol} / \mathrm{L}$ at 12 months and $12.0 \pm 2.8 \mu \mathrm{mol} / \mathrm{L}$ at 24 months) compared with the supplementation group ( $9.6 \pm 2.6$ $\mu \mathrm{mol} / \mathrm{L}$ to $9.8 \pm 2.4 \mu \mathrm{mol} / \mathrm{L}$ at $12 \mathrm{months}$ to $10.4 \pm 4.5 \mu \mathrm{mol} / \mathrm{L}$ at 24 months). These results showed that, within the FA group, Hcy levels increased significantly more in those taking antidepressants compared with those not taking antidepressants $(p=0.021)$.

One study ${ }^{69}$ determined the effect of adjunctive L-MTHF supplementation in the treatment of major depression amongst patients who had previously failed to adequately respond to selective seratonin reuptake inhibitors. In this study, participants were stratified according to baseline body mass index (BMI), levels of plasma hs-CRP, 4-hydroxy-2-nonenal (4-HNE), SAMe/SAH ratio, and various genetic polymorphisms. Overall results indicated that adjunctive treatment with $15 \mathrm{mg}$ /day of L-MTHF resulted in a greater mean change on the HDRS than placebo $(-6.8 \pm 7.2 v s .-3.7 \pm 6.5$; $p=0.017)$. When the results were further analyzed by subgroups, there were significant changes (all, $p<0.05$ ). Firstly, patients with a baseline plasma SAMe/SAH ratio below the study median value, hs-CRP or 4-HNE blood levels above the study median value or a $\mathrm{BMI} \geq 30 \mathrm{~kg} / \mathrm{m}^{2}$, had a greater mean change on the HDRS-28 in the L-MTHF group compared with placebo $(p \leq 0.05)$. This significant effect of L-MTHF on HDRS scores was also observed for most genetic markers including COMT GG $(p<0.001)$ COMT CC $(p$ $<0.001)$, MTR AG/GG $(p=0.001)$ and RFC1 AA $(p=0.003)$ and for most combinations of both biological and genetic markers and different genetic markers. These included the following: MTHFR $677 \mathrm{CT} / \mathrm{TT}$ and MTR $2756 \mathrm{AG} / \mathrm{GG}(p<0.001)$; BMI $\geq 30 \mathrm{~kg} / \mathrm{m}^{2}$ and MTR $2756 \mathrm{AG} / \mathrm{GG}(p<0.001)$; DNAMT3B AG/AA and MTR $2756 \mathrm{AG} / \mathrm{GG}(p<0.001)$, MTHFR $677 \mathrm{CT} / \mathrm{TT}$ with BMI $\geq 30 \mathrm{~kg}$ $\mathrm{m}^{2}(p<0.001)$. This highlights that folate metabolism is influenced by individual metabolic and genetic factors, which in turn could identify people both at risk of major depressive disorder and those who may not respond adequately to antidepressant treatment.

\section{FA supplementation as standalone therapy in prevention of de- pression}

Three trials ${ }^{38,71,72}$ examined the effect of FA supplementation as a standalone treatment in the prevention of depression, and all three studies found no difference in depressive symptoms between the groups. A summary of each of the studies is included in Table 2. In the trial by De Koning et al., ${ }^{71} 2919$ participants (mean age, 74.1 \pm 6.5 ) were randomized to receive either a placebo containing 15 $\mu \mathrm{g}$ of vitamin $\mathrm{D}_{3}$, or the intervention tablet containing $40 \mu \mathrm{g}$ of FA, $500 \mu \mathrm{g}$ vitamin $\mathrm{B}_{12}$ and $15 \mu \mathrm{g}$ of vitamin $\mathrm{D}_{3}$ per day for 2 years. While the primary outcome measure was assessment of the impact of this supplement regime on bone fracture risk, a secondary outcome measure was depressive symptoms as measured by the HDRS-17. Participants were included in this study if they had elevated Hcy concentrations (range: $12-50 \mu \mathrm{mol} / \mathrm{L}$ ), with the mean baseline concentrations being $14.3 \mu \mathrm{mol} / \mathrm{L}$ in the intervention group and $14.5 \mu \mathrm{mol} / \mathrm{L}$ in the placebo group. The aim of the study was to determine whether the FA and vitamin $\mathrm{B}_{12}$ supplementation would decrease Hcy levels and, in turn, have an impact on depressive symptoms. The Hcy did indeed decrease significantly more in the supplemented group compared to placebo over the 2-year intervention (placebo: $-0.2 \pm 4.1 \mu \mathrm{mol} / \mathrm{L}$; intervention: $-4.4 \pm 3.3 \mu \mathrm{mol} / \mathrm{L}$; $p<0.001)$. However, the rate of depressive symptoms between the groups did not differ (OR: $1.13,95 \%$ CI: $0.83-1.53 ; p=0.45$ ).

In a similarly large trial $(n=4331)$, Okereke et al. ${ }^{72}$ studied the effect of supplementing $2.5 \mathrm{mg}$ FA, $50 \mathrm{mg}$ vitamin $\mathrm{B}_{6}$ and $1 \mathrm{mg}$ 
vitamin $\mathrm{B}_{12}$ for 7.3 years in older women (mean age, $63.6 \pm 8.7$ years). As with the De Koning study, ${ }^{71}$ depression was a secondary outcome (CVD was the primary outcome), and it was determined using the Mental Health Inventory. Despite a reduction in Hcy levels in the supplementation group, there was no significant effect on depressive symptoms in comparison to placebo (relative risk: 1.02 ; $95 \%$ CI: $0.86-1.21 ; p=0.81)$. The findings did not change when analyzed according to age (i.e. rates of depression varied for $<65$ years compared to $>65$ years) and there was no impact of Bvitamins on depression risk according to age (all, $p>0.05$ ).

The only trial to examine the effect of FA supplementation on mood in non-depressed, otherwise healthy individuals, was by Williams et al. ${ }^{38}$ in 2005 . This small trial randomized 28 males (mean age, 32 years) to receive either placebo or intervention of $100 \mu \mathrm{g}$ FA for 6 weeks followed by $200 \mu \mathrm{g}$ FA for 6 weeks. Subjective mood was measured and inferred using the Positive and Negative Affect Score, and biochemical markers included RCF, serum folate, Hcy and whole blood serotonin. Although this was a folate-replete sample, the participants had Hcy levels within the normal range. Following supplementation, even the relative low dose (100-200 $\mu \mathrm{g} /$ day) significantly increased serum folate levels at $100 \mu \mathrm{g} /$ day $(p=0.043)$ and $200 \mu \mathrm{g} /$ day $(p=0.024)$. Hcy also decreased at both $100 \mu \mathrm{g} /$ day $(p=0.032)$ and $200 \mu \mathrm{g} /$ day $(p=0.015)$ supplementation levels. However, neither subjective mood (all, $p$ $>0.05)$ nor whole blood serotonin $(p=0.816)$ differed between the two groups post-intervention.

We did not attempt to meta-analyze the data due to the wide variety of depression outcomes measured, the differences in the doses given for each intervention, the inclusion of vitamins in some of the trials, and the considerable heterogeneity observed between the cohorts studied.

\section{Discussion}

The majority of the ten studies included were human clinical trials that explored the relationship between Hcy, folate and depression scores at baseline, and whether FA supplementation improved depressive symptoms. Only the trial of L-MTHF explored the interplay of genetic polymorphisms and underlying inflammatory biomarkers. The overall findings suggest that there is little evidence to support the use of FA as an adjunct to antidepressants in the treatment of depression, or as a standalone therapy in the prevention of depression. There may be some benefit in the use of L-MTHF. However, as there was only one trial of L-MTHF included in this review, with a relatively small number of participants $(n=75),{ }^{69}$ further research is needed to guide recommendations for this form of folate. Similarly, there was significant heterogeneity amongst the trials within this review, making it difficult to elucidate a clear effect or benefit of FA on either Hcy or depression.

Although it was observed in four trials ${ }^{65,68,70,73}$ that FA supplementation lowered Hcy, the effect on depressive symptoms was somewhat equivocal. It should be noted that these trials were of a relatively small size (range, 24-153), recruited predominantly females $(65 \%)$, and apart from the trial by Almeida et al., ${ }^{65}$ were relatively short in duration. Interestingly, the trial by Coppen et $a l .{ }^{68}$ is the earliest published trial in this review, and it is the only trial where data was analyzed based on differences in sex. While the authors found an overall positive effect for FA on both Hcy and depression, when analyzed by sex, they found this effect only extended to females on both measures. The authors noted that the males had a smaller increase in plasma folate compared with the females (males, $4.58 \pm 1.68 \mathrm{ng} / \mathrm{mL}$ to $8.70 \pm 3.50 \mathrm{ng} / \mathrm{mL}, p$
$<0.001$; females, $4.04 \pm 1.64 \mathrm{ng} / \mathrm{mL}$ to $12.70 \pm 1.65 \mathrm{ng} / \mathrm{mL}, p<$ $0.001)$ and this may have been insufficient to illicit a decrease in plasma Hcy. Further, they argued that the failure to decrease Hcy in males may explain why they did not improve their depressive symptoms as measured by the HDRS.

The study by Almeida et al. ${ }^{65}$ did not analyze data by sex, despite being of a much longer duration (52 weeks) and using a higher dose of FA ( $2 \mathrm{mg})$. Moreover, the trial also contained a larger proportion of males (44\%) and was conducted in an older population (treatment, mean age: $61.7 \pm 8.2$ years); placebo, mean age: $63.4 \pm 7.4$ years). This is an important consideration as Hcy is known to increase with age. ${ }^{77,78}$ In contrast, the trials by Resler et al..$^{70}$ and Loria-Kohen et al. ${ }^{73}$ contained mostly female participants $(>85 \%)$, with an average age of 24.2 years and 35.04 years respectively, and supplemented with $10 \mathrm{mg} /$ day of FA. Although Resler et al..$^{70}$ reported a lowering of Hcy in the supplemented group, this was not associated with a change in clinical symptoms. Rather, in this trial, a reduction in 5-HIAA was noted in patients receiving FA and it was postulated that the main effect of FA was due to modification of the serotonergic system in lymphocytes. Loria-Kohen et $a l . .^{73}$ also reported a lowering of Hcy; however, the results show that Hcy decreased comparably in both intervention and placebo (intervention: $9.4 \pm 2.4 \mu \mathrm{mol} / \mathrm{L}$ to $7.5 \pm 1.7 \mu \mathrm{mol} / \mathrm{L}$; placebo: 10.0 $\pm 2.05 \mu \mathrm{mol} / \mathrm{L}$ to $8.0 \pm 1.8 \mu \mathrm{mol} / \mathrm{L}$ ). The authors also reported this result as a significant reduction for the intervention group $(p<$ $0.01)$ but not in the placebo group. In addition, the baseline RCF (intervention: $634.3 \pm 300.0 \mathrm{ng} / \mathrm{mL}$ vs. placebo: $844.4 \pm 285.4 \mathrm{ng} /$ $\mathrm{mL}$ ) and vitamin $\mathrm{B}_{12}$ levels (intervention: $562.6 \pm 209.5 \mathrm{pg} / \mathrm{mL}$ vs. placebo: $782.0 \pm 387.0 \mathrm{pg} / \mathrm{mL}$ ) were higher pre-intervention in the placebo group compared to the supplemented group. Based on these results, it is difficult to attribute the reduction in depressive symptoms to the lowering of Hcy, while the discrepancy in baseline biochemical status may be confounding the results.

Of the five remaining trials, there was no evidence that FA enhanced the effect of antidepressants or prevented depression as a standalone treatment. ${ }^{38,66,67,71,72}$ Four were large trials (range, $475-4331)$ and three had a duration of 2 years or more, ${ }^{66,67,71,72}$ while dosage ranged from $0.1-5 \mathrm{mg} /$ day. Overall, these trials found there was no correlation between a reduction in Hcy and depressive symptoms. Interestingly, in contrast to the study by Coppen et al. ${ }^{68}$ the trial by Okereke et al. ${ }^{72}$ found that a reduction in Hcy did not reduce depressive symptoms in women in comparison with placebo. This was a large trial with only female participants $(n=4331)$, used a relatively high FA dosage $(2.5 \mathrm{mg} /$ day $)$, and was conducted for 7.3 years; therefore, the findings suggested that the conclusion reached by Coppen et al. ${ }^{68}$ may have been confounded by other factors. Similarly, in two other relatively long term trials (2 years) with large cohorts, Christensen et al. ${ }^{67}$ and De Koning et $a l .{ }^{71}$ found no relationship between a reduction in Hcy and depression scores. Subsequent analysis of the participants' DNA revealed altered methylation patterns in the FA and vitamin $\mathrm{B}_{12}$ group versus the placebo group,${ }^{14}$ further supporting the impact of long-term FA exposure on the epigenome and thus gene expression, not just during vital developmental periods but into older age as well.

Only one included trial examined the use of L-MTHF (15 mg/ day) and the relevance of biomarkers other than Hcy (hs-CRP, $\mathrm{SAMe} / \mathrm{SAH}$ ratio, $4-\mathrm{HNE}){ }^{69}$ and the effect of genetic markers on treatment response in comparison to placebo. As L-MTHF is the form of folate predominantly found in food, ${ }^{17}$ it could be argued that it makes more sense to examine how this naturally occurring form interacts with human biochemistry, neurochemistry and genetics. In this trial, L-MTHF was significantly more effective overall than placebo in reducing depression as measured by the HDRS-28. The results became more interesting when they were 
analyzed according to subgroup, which showed that L-MTHF was more effective in patients with elevated hs-CRP or 4-HNE, a BMI $>30 \mathrm{~kg} / \mathrm{m}^{2}$, or a plasma SAMe/SAH ratio below the study mean. Similarly, patients with the MTR 2756 AG/GG or MTRR 66 AG/ GG genotypes, compared with the homozygous dominant alleles, had a significantly greater HDRS-28 response on L-MTHF compared with placebo. However, this was not observed for the MTHFR 677CT/TT or MTHFR 1298 AC/CC genotypes. This observation is interesting given that research has been conducted to identify the potential role of MTHFR in altered folate metabolism. ${ }^{50,51,60,79-81}$ Similarly, the measurement of SAMe/SAH is interesting as this is an indicator of methylation status, with a low $\mathrm{SAMe} / \mathrm{SAH}$ ratio indicating impaired methylation. Although the trial was only 60 days in duration, and had only 75 participants, this study served to highlight the fundamental importance of genetics in folate metabolism.

No relevant randomized controlled trials were located for this review examining the efficacy of folinic acid in the treatment or prevention of depression. Future randomized controlled trials investigating folinic acid and depressive symptoms would be of interest to evaluate in this population. Folinic acid is a natural metabolite of THF; therefore, its pathway through the folate cycle is regulated by homeostatic processes. ${ }^{17}$ This contrasts with L-MTHF supplementation, which may lead to risk of $\mathrm{B}_{12}$ deficiency if consumed at supraphysiological doses. ${ }^{17,82}$ Similarly, this review did not examine trials in individuals with autism, schizophrenia or bipolar depression due to the more complex neurochemical processes and different pathophysiology of these disorders. However, it is acknowledged that the role of folate and FA in these disorders has caused similar controversy and warrants further research that may provide insight into the treatment of depressive symptoms. ${ }^{83-87}$

\section{Future research directions}

Historically, most of the research has focused on exploring whether lowering Hcy with FA supplementation reduces depression symptoms or risk of depression. However, findings of this review suggest that the link between Hcy and depression is tenuous. The trial by Papakostas et al. ${ }^{69}$ disbanded examination of Hcy in favor of exploring the interplay of genetic polymorphisms, inflammatory biomarkers (i.e. hs-CRP and 4-HNE) and methylation status (SAMe/ SAH ratio). ${ }^{88}$ To our knowledge, this is the only human randomized controlled trial using L-MTHF in individuals with depression.

Further research into the use of L-MTHF as an alternative to FA is clearly needed, as L-MTHF is both the naturally occurring and the biologically active form of folate. ${ }^{17}$ While Papakostas et al. ${ }^{69}$ demonstrated a differential effect of 5-MTHF based on numerous genetic and biological markers, it would be pertinent to explore if these same markers would be indicative of an impaired or similarly differential response with FA treatment. This trial also highlights that further research is needed into the genetic polymorphisms that impact upon folate metabolism, and how in turn they may impact upon depression risk or symptoms.

Research into the differential metabolism of FA compared to 5-MTHF in relation to its impact on depression is also needed. DHF is the intermediate metabolite in FA metabolism and acts to inhibit key enzymes in the folate cycle, while slowing down the biotransformation of FA to its active forms. ${ }^{20}$ The possible consequences may be that non-metabolized FA in the plasma is left to compete with biologically active forms for transport into the central nervous system, and that intracellular folate metabolism is impaired by the FA intermediates. ${ }^{4,21}$ Moreover, the MTHFR gene has been extensively studied due to the observation that carriers of the C677T variant have reduced enzyme function, resulting in both increased levels of Hcy and an increased risk of depression. ${ }^{89,90}$ Therefore, it is hypothesized (Fig. 2) that supplemental FA is inhibiting MTHFR by DHF, thus impairing folate metabolism further in people with the MTHFR C677T mutation and resulting in a functional deficiency of folate.

Perhaps an important point to consider is that the fundamental role of folate is the donation and de novo synthesis of methyl groups. While both 5-MTHF and FA are capable of de novo synthesis, only 5-MTHF contributes new methyl groups to the human system. Consequently, research that adequately compares the biological functioning of the natural versus synthetic forms of folate, and the impact on depression symptoms and risk of developing depression, would be extremely valuable.

Furthermore, exploring how existing FA supplementation and fortification may be affecting genetic expression, and in turn whether FA is increasing the risk, incidence and prevalence of depression is needed. There is increasing evidence that folate plays a fundamental role in the epigenetic modification of the human genome, with methylation in particular serving to either silence or promote the transcription of genes. While impaired folate metabolism caused by FA supplementation can result in hypomethylation, it is unknown what impact un-metabolized FA has on human health and disease. If it can be demonstrated that FA is altering methylation patterns in genetically-susceptible individuals, then the implications for depression and many modern noncommunicable diseases could be quite profound.

Finally, increases in latitude are associated with an increased frequency of the MTHFR-C677T and MTHFR-A1298C polymorphisms, suggesting a link between latitude and depression in the context of folate intake is worthy of further investigation. ${ }^{91}$

\section{Conclusions}

The biochemistry of folate and FA is both complex and fascinating. Folate plays an integral role at our most fundamental level, that of controlling and modifying genetic expression. The findings of this review suggest that there is limited evidence to suggest benefits to folate supplementation in the treatment or management of depression. However, further research investigating the benefits of L-MTHF and folinic acid supplementation in individuals with depression is warranted. In addition, methylation status and the interaction of various genetic polymorphisms associated with folate metabolism may influence the efficacy of folate supplementation.

Depressive symptoms can be debilitating and many of the pharmacological agents employed to treat them can have significant side effects. The challenge of the human condition is that we desire to find an answer in a capsule rather than consuming a dietary pattern based on minimally processed foods such as green leafy vegetables. Future research should assess the potential for these supplements to cause epigenetic changes to our DNA in individuals with certain genetic polymorphisms that may be heritable across future generations. Therefore, it is worth questioning whether the current supplementation of FA is appropriate, and whether other forms of folate, such as L-MTHF or folinic acid, may prove to be safer alternatives.

\section{Conflict of interest}

The authors have no conflict of interest related to this publication. 


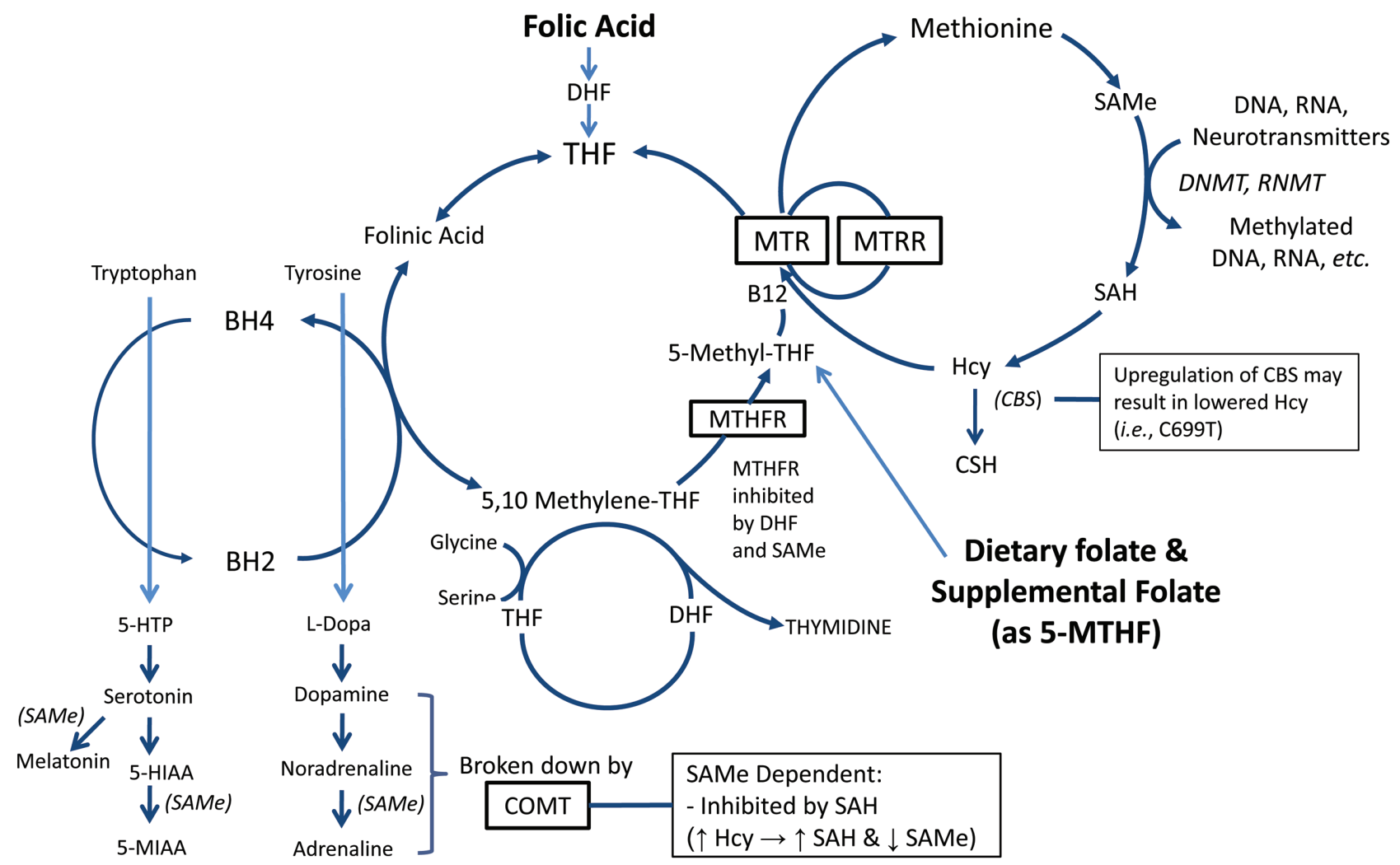

Neurotransmitters: Serotonin, Dopamine, Noradrenaline, Adrenaline

Fig. 2. Relationship between folate, methylation and neurotransmitters involved with depression. It is hypothesized that consumption of FA may result in decreased neurotransmitter production due to decreased availability of biologically active folate 5-MTHF and a resulting decrease in SAMe. Moreover, the addition of FA into a finely balanced yet complicated cycle in susceptible individuals (e.g., those with MTHFR, MTR, MTRR and COMT polymorphisms) may serve to greatly slow the cycle via the inhibition of MTHFR by DHF. As the population continues to consume less folate from food sources such as leafy green vegetables, then it is postulated that the rates and severity of depression will increase as 5-MTHF decreases. Abbreviations: DHF, dihydrofolate; FA, folic acid; 5-MTHF, 5-methyltetrahydrofolate; MTHFR, methylenetetrahydrofolate reductase; SAMe, S-adenosylmethionine.

\section{Author contributions}

Conducted initial searches and formulated the first draft of the manuscript (HB, NMD), critically evaluated the papers, search procedures and assisted with the risk of bias assessment (ENG), critically reviewed the paper and provided the input into the study design and assisted with analysis and interpretation of studies (JK, DM, AM); designed the study, monitored the study design, all protocols and supervised the students involved in this paper (NN, HB, NMD); All authors included contributed significantly to the final manuscript.

\section{Supporting information}

Supplementary material for this article is available at https://doi. org/10.14218/ERHM.2017.00025.

Supplementary information 1. Measures of depressive symptoms.

\section{References}

[1] MRC Vitamin Study Research Group. Prevention of neural tube defects: results of the Medical Research Council Vitamin Study. Lancet
1991;338(8760):131-137. doi:10.1016/0140-6736(91)90133-A.

[2] Berry RJ, Li Z, Erickson JD, Li S, Moore CA, Wang H, et al. Prevention of neural-tube defects with folic acid in China. China-U.S. Collaborative Project for Neural Tube Defect Prevention. N Engl J Med 1999;341(20):1485-1490. doi:10.1056/NEJM199911113412001.

[3] Smith AD, Refsum H, Selhub J, Rosenberg IH. Decision on folic acid fortification in Europe must consider both risks and benefits. BMJ 2016;352:i734. doi:10.1136/bmj.i734.

[4] Lucock M, Yates Z. Folic acid fortification: a double-edged sword. Curr Opin Clin Nutr Metab Care 2009;12(6):555-564. doi:10.1097/ MCO.0b013e32833192bc.

[5] Crider KS, Bailey LB, Berry RJ. Folic Acid Food Fortification - Its History, Effect, Concerns, and Future Directions. Nutrients 2011;3(3):370384. doi:10.3390/nu3030370.

[6] Beckett EL, Martin C, Boyd L, Porter T, King K, Niblett S, et al. Reduced plasma homocysteine levels in elderly Australians following mandatory folic acid fortification - A comparison of two cross-sectional cohorts. J Nutr Intermed Metab 2017;8:14-20. doi:10.1016/j. jnim.2017.04.001.

[7] Verly-Jr E, Steluti J, Fisberg RM, Marchioni DM. A quantile regression approach can reveal the effect of fruit and vegetable consumption on plasma homocysteine levels. PLoS One 2014;9(11):e111619. doi:10.1371/journal.pone.0111619.

[8] Agodi A, Barchitta M, Quattrocchi A, Maugeri A, Canto C, Marchese $\mathrm{AE}$, et al. Low fruit consumption and folate deficiency are associated with LINE-1 hypomethylation in women of a cancer-free population. Genes Nutr 2015;10(5):480. doi:10.1007/s12263-015-0480-4. 
[9] Patel KR, Sobczynska-Malefora A. The adverse effects of an excessive folic acid intake. Eur J Clin Nutr 2017;71(2):159-163. doi:10.1038/ ejcn.2016.194.

[10] Bailey LB, Stover PJ, McNulty H, Fenech MF, Gregory JF 3rd, Mills JL, et al. Biomarkers of nutrition for development-folate review. J Nutr 2015;145(7):1636S-1680S. doi:10.3945/jn.114.206599.

[11] FoodStandardsAustraliaNewZealand.Consideration ofmandatoryfortification with folicacid. Food Standards Australia;2007. Availablefrom: http://www.foodstandards.gov.au/code/proposals/pages/proposalp 295considerationofmandatoryfortificationwithfolicacid/Default. aspx.

[12] Harb H, Amarasekera M, Ashley S, Tulic MK, Pfefferle PI, Potaczek DP, et al. Epigenetic regulation in early childhood: a miniaturized and validated method to assess histone acetylation. Int Arch Allergy Immunol 2015;168(3):173-181. doi:10.1159/000442158.

[13] Garcia BA, Luka Z, Loukachevitch LV, Bhanu NV, Wagner C. Folate deficiency affects histone methylation. Med Hypotheses 2016;88:6367. doi:10.1016/j.mehy.2015.12.027

[14] Kok DE, Dhonukshe-Rutten RA, Lute C, Heil SG, Uitterlinden AG, van der Velde $\mathrm{N}$, et al. The effects of long-term daily folic acid and vitamin B12 supplementation on genome-wide DNA methylation in elderly subjects. Clin Epigenetics 2015;7:121. doi:10.1186/s13148-0150154-5.

[15] Paniz C, Bertinato JF, Lucena MR, De Carli E, Amorim P, Gomes GW, et al. A daily dose of $5 \mathrm{mg}$ folic acid for 90 days is associated with increased serum unmetabolized folic acid and reduced natural killer cell cytotoxicity in healthy Brazilian adults. J Nutr 2017;147(9):16771685. doi:10.3945/jn.117.247445.

[16] Kelly KB, Kennelly JP, Ordonez M, Nelson R, Leonard K, Stabler S, et al. Excess folic acid increases lipid storage, weight gain, and adipose tissue inflammation in high fat diet-fed rats. Nutrients 2016;8(10):E594. doi:10.3390/nu8100594.

[17] Lucock M. Folic acid: nutritional biochemistry, molecular biology, and role in disease processes. Mol Genet Metab 2000;71(1-2):121-138. doi:10.1006/mgme.2000.3027.

[18] Thien KR, Blair JA, Leeming RJ, Cooke WT, Melikian V. Serum folates in man. J Clin Pathol 1977;30(5):438-448.

[19] Hoffbrand AV, Weir DG. The history of folic acid. Br J Haematol 2001;113(3):579-589. doi:10.1046/j.1365-2141.2001.02822.x.

[20] Choi JH, Yates Z, Veysey M, Heo YR, Lucock M. Contemporary issues surrounding folic Acid fortification initiatives. Prev Nutr Food Sci 2014;19(4):247-260. doi:10.3746/pnf.2014.19.4.247.

[21] Lucock M. Is folic acid the ultimate functional food component for disease prevention? BMJ 2004;328(7433):211-214. doi:10.1136/ bmj.328.7433.211.

[22] Kelly P, McPartlin J, Goggins M, Weir DG, Scott JM. Unmetabolized folic acid in serum: acute studies in subjects consuming fortified food and supplements. Am J Clin Nutr 1997;65(6):1790-1795.

[23] Fenech $M$. The role of folic acid and Vitamin B12 in genomic stability of human cells. Mutat Res 2001;475(1-2):57-67. doi:10.1016/S00275107(01)00079-3.

[24] Green R, Datta Mitra A. Megaloblastic anemias: nutritional and other causes. Med Clin North Am 2017;101(2):297-317. doi:10.1016/j. mcna.2016.09.013.

[25] Kim YI. Folate and colorectal cancer: An evidence-based critical review. Mol Nutr Food Res 2007;51(3):267-292. doi:10.1002/mnfr. 200600191.

[26] Kim YI. Role of folate in colon cancer development and progression. J Nutr 2003;133(11 Suppl 1):3731S-3739S.

[27] Kim YI. Does a high folate intake increase the risk of breast cancer? Nutr Rev 2006;64(10):468-475. doi:10.1111/j.1753-4887.2006.tb00 178.x.

[28] Ulrich CM, Potter JD. Folate supplementation: too much of a good thing? Cancer Epidemiol Biomarkers Prev 2006;15(2):189-193. doi:10.1158/1055-9965.EPI-152CO.

[29] Ganguly P, Alam SF. Role of homocysteine in the development of cardiovascular disease. Nutr J 2015;14:6. doi:10.1186/1475-2891-14-6.

[30] Xiao Y, Su X, Huang W, Zhang J, Peng C, Huang H, et al. Role of Sadenosylhomocysteine in cardiovascular disease and its potential epigenetic mechanism. Int J Biochem Cell Biol 2015;67:158-166. doi:10.1016/j.biocel.2015.06.015.
[31] Bottiglieri T, Laundy M, Crellin R, Toone BK, Carney MW, Reynolds $\mathrm{EH}$. Homocysteine, folate, methylation, and monoamine metabolism in depression. J Neurol Neurosurg Psychiatry 2000;69(2):228-232. doi:10.1136/jnnp.69.2.228.

[32] Paul RT, McDonnell AP, Kelly CB. Folic acid: neurochemistry, metabolism and relationship to depression. Hum Psychopharmacol 2004;19(7):477-488. doi:10.1002/hup.614.

[33] Sarris J, Murphy J, Mischoulon D, Papakostas GI, Fava M, Berk M, et al. Adjunctive nutraceuticals for depression: a systematic review and meta-analyses. Am J Psychiatry 2016;173(6):575-587. doi:10.1176/ appi.ajp.2016.15091228.

[34] Taylor MJ, Carney S, Geddes J, Goodwin G. Folate for depressive disorders. Cochrane Database Syst Rev 2003(2):CD003390. doi:10.1002/14651858.CD003390.

[35] Almeida OP, Ford AH, Flicker L. Systematic review and meta-analysis of randomized placebo-controlled trials of folate and vitamin B12 for depression. Int Psychogeriatr 2015;27(5):727-737. doi:10.1017/ S1041610215000046.

[36] Chalupsky K, Kracun D, Kanchev I, Bertram K, Gorlach A. Folic acid promotes recycling of tetrahydrobiopterin and protects against hypoxia-induced pulmonary hypertension by recoupling endothelial nitric oxide synthase. Antioxid Redox Signal 2015;23(14):1076-1091. doi:10.1089/ars.2015.6329.

[37] Stanhewicz AE, Kenney WL. Role of folic acid in nitric oxide bioavailability and vascular endothelial function. Nutr Rev 2017;75(1):61-70. doi:10.1093/nutrit/nuw053.

[38] Williams E, Stewart-Knox B, Bradbury I, Rowland I, Pentieva K, Helander $A$, et al. Effect of folic acid supplementation on mood and serotonin response in healthy males. Br J Nutr 2005;94(4):602-608. doi:10.1079/BJN20051501.

[39] Botez MI, Young SN, Bachevalier J, Gauthier S. Folate deficiency and decreased brain 5-hydroxytryptamine synthesis in man and rat. $\mathrm{Na}$ ture 1979;278(5700):182-183. doi:10.1038/278182a0.

[40] Carney MW. Serum folate values in 423 psychiatric patients. Br Med J 1967;4(5578):512-516.

[41] Reynolds EH, Preece JM, Bailey J, Coppen A. Folate deficiency in depressive illness. Br J Psychiatry 1970;117(538):287-292. doi:10.1192/ bjp.117.538.287.

[42] Ghadirian AM, Ananth J, Engelsmann F. Folic acid deficiency and depression. Psychosomatics 1980;21(11):926-929. doi:10.1016/S00333182(80)73586-7.

[43] Wesson VA, Levitt AJ, Joffe RT. Change in folate status with antidepressant treatment. Psychiatry Res 1994;53(3):313-322. doi:10.1016/ 0165-1781(94)90058-2.

[44] Fava M, Borus JS, Alpert JE, Nierenberg AA, Rosenbaum JF, Bottiglieri T. Folate, vitamin B12, and homocysteine in major depressive disorder. Am J Psychiatry 1997;154(3):426-428. doi:10.1176/ ajp.154.3.426.

[45] Lucock MD. Synergy of genes and nutrients: the case of homocysteine. Curr Opin Clin Nutr Metab Care 2006;9(6):748-756. doi:10.1097/01.mco.0000247468.18790.1e.

[46] Schatz RA, Wilens TE, Sellinger OZ. Decreased in vivo protein and phospholipid methylation after in vivo elevation of brain S-adenosylhomocysteine. Biochem Biophys Res Commun 1981;98(4):10971107. doi:10.1016/0006-291X(81)91224-9.

[47] Kalani A, Kamat PK, Givvimani S, Brown K, Metreveli N, Tyagi SC, et al. Nutri-epigenetics ameliorates blood-brain barrier damage and neurodegeneration in hyperhomocysteinemia: role of folic acid. J Mol Neurosci 2014;52(2):202-215. doi:10.1007/s12031-013-0122-5.

[48] Smith DE, Smulders YM, Blom HJ, Popp J, Jessen F, Semmler A, et al. Determinants of the essential one-carbon metabolism metabolites, homocysteine, S-adenosylmethionine, S-adenosylhomocysteine and folate, in cerebrospinal fluid. Clin Chem Lab Med 2012;50(9):16411647. doi:10.1515/cclm-2012-0056.

[49] Peerbooms OLJ, van Os J, Drukker M, Kenis G, Hoogveld L, de Hert M et al. Meta-analysis of MTHFR gene variants in schizophrenia, bipolar disorder and unipolar depressive disorder: Evidence for a common genetic vulnerability? Brain Behav Immun 2011;25(8):1530-1543. doi:10.1016/j.bbi.2010.12.006.

[50] Wu Y-L, Ding X-X, Sun Y-H, Yang H-Y, Chen J, Zhao X, et al. Association between MTHFR C677T polymorphism and depression: An updated 
meta-analysis of 26 studies. Prog Neuropsychopharmacol Biol Psychiatry 2013;46:78-85. doi:10.1016/j.pnpbp.2013.06.015.

[51] Velichko VL, Kudlach OI, Shelepina OA. A Study of occurrence frequency of $6677 \mathrm{t}$ polymorphism of the gene MTHFR and plasma folate levels in patients with unipolar depression. Lik Sprava 2015(12):156-157.

[52] Sharpley AL, Hockney R, McPeake L, Geddes JR, Cowen PJ. Folic acid supplementation for prevention of mood disorders in young people at familial risk: a randomised, double blind, placebo controlled trial. J Affect Disord 2014;167:306-311. doi:10.1016/j.jad.2014.06.011.

[53] Roffman JL, Lamberti JS, Achtyes E, Macklin EA, Galendez GC, Raeke $\mathrm{LH}$, et al. Randomized multicenter investigation of folate plus vitamin B12 supplementation in schizophrenia. JAMA Psychiatry 2013;70(5):481-489. doi:10.1001/jamapsychiatry.2013.900.

[54] Godfrey PS, Toone BK, Carney MW, Flynn TG, Bottiglieri T, Laundy $\mathrm{M}$, et al. Enhancement of recovery from psychiatric illness by methylfolate. Lancet 1990;336(8712):392-395. doi:10.1016/01406736(90)91942-4.

[55] Passeri M, Cucinotta D, Abate G, Senin U, Ventura A, Stramba Badiale $M$, et al. Oral 5'-methyltetrahydrofolic acid in senile organic mental disorders with depression: results of a double-blind multicenter study. Aging (Milano) 1993;5(1):63-71. doi:10.1007/BF03324128.

[56] Obeid R, Kirsch SH, Kasoha M, Eckert R, Herrmann W. Concentrations of unmetabolized folic acid and primary folate forms in plasma after folic acid treatment in older adults. Metabolism 2011;60(5):673680. doi:10.1016/j.metabol.2010.06.020.

[57] Smith AD, Kim YI, Refsum H. Is folic acid good for everyone? Am J Clin Nutr 2008;87(3):517-533.

[58] Brustolin S, Giugliani R, Felix TM. Genetics of homocysteine metabolism and associated disorders. Braz J Med Biol Res 2010;43(1):1-7. doi:10.1590/S0100-879X2009007500021.

[59] Bueno O, Molloy AM, Fernandez-Ballart JD, Garcia-Minguillan CJ, Ceruelo $\mathrm{S}$, Rios $\mathrm{L}$, et al. Common polymorphisms that affect folate transport or metabolism modify the effect of the MTHFR $677 \mathrm{C}>\mathrm{T}$ polymorphism on folate status. J Nutr 2016;146(1):1-8. doi:10.3945/ jn.115.223685.

[60] Christensen KE, Mikael LG, Leung KY, Levesque N, Deng L, Wu Q, et al. High folic acid consumption leads to pseudo-MTHFR deficiency, altered lipid metabolism, and liver injury in mice. Am J Clin Nutr 2015;101(3):646-658. doi:10.3945/ajcn.114.086603.

[61] Fang JY, Xiao SD. Folic acid, polymorphism of methyl-group metabolism genes, and DNA methylation in relation to Gl carcinogenesis. J Gastroenterol 2003;38(9):821-829. doi:10.1007/s00535-003-12077.

[62] Moher D, Liberati A, Tetzlaff J, Altman DG, The PRISMA Group. Preferred reporting items for systematic reviews and meta-analyses: the PRISMA statement. J Clin Epidemiol 2009;62(10):1006-1012. doi:10.1371/journal.pmed.1000097.

[63] Hallert C, Svensson M, Tholstrup J, Hultberg B. Clinical trial: B vitamins improve health in patients with coeliac disease living on a gluten-free diet. Aliment Pharmacol Ther 2009;29(8):811-816. doi:10.1111/j.1365-2036.2009.03945.x.

[64] Bochynska A, Lipczynska-Lojkowska W, Gugala-Iwaniuk M, Lechowicz W, Restel M, Graban A, et al. The effect of vitamin B supplementation on homocysteine metabolism and clinical state of patients with chronic epilepsy treated with carbamazepine and valproic acid. Seizure 2012;21(4):276-281. doi:10.1016/j.seizure.2012.01.013.

[65] Almeida OP, Ford AH, Hirani V, Singh V, vanBockxmeer FM, McCaul $\mathrm{K}$, et al. B vitamins to enhance treatment response to antidepressants in middle-aged and older adults: results from the B-VITAGE randomised, double-blind, placebo-controlled trial. Br J Psychiatry 2014;205(6):450-457. doi:10.1192/bjp.bp.114.145177.

[66] Bedson E, Bell D, Carr D, Carter B, Hughes D, Jorgensen A, et al. Folate Augmentation of Treatment-Evaluation for Depression (FolATED): randomised trial and economic evaluation. Health Technol Assess 2014;18(48):vii-viii, 1-159. doi:10.3310/hta18480.

[67] Christensen H, Aiken A, Batterham PJ, Walker J, Mackinnon AJ, Fenech $\mathrm{M}$, et al. No clear potentiation of antidepressant medication effects by folic acid+vitamin B12 in a large community sample. J Affect Disord 2011;130(1-2):37-45. doi:10.1016/j.jad.2010.07.029.

[68] Coppen A, Bailey J. Enhancement of the antidepressant action of fluoxetine by folic acid: a randomised, placebo controlled trial. J Affect Disord 2000;60(2):121-130. doi:10.1016/S0165-0327(00)00153-1.

[69] Papakostas GI, Shelton RC, Zajecka JM, Bottiglieri T, Roffman J, Cassiello $\mathrm{C}$, et al. Effect of adjunctive L-methylfolate $15 \mathrm{mg}$ among inadequate responders to SSRIs in depressed patients who were stratified by biomarker levels and genotype: results from a randomized clinical trial. J Clin Psychiatry 2014;75(8):855-863. doi:10.4088/ JCP.13m08947.

[70] Resler G, Lavie R, Campos J, Mata S, Urbina M, Garcia A, et al. Effect of folic acid combined with fluoxetine in patients with major depression on plasma homocysteine and vitamin B12, and serotonin levels in lymphocytes. Neuroimmunomodulation 2008;15(3):145-152. doi:10.1159/000151527.

[71] de Koning EJ, van der Zwaluw NL, van Wijngaarden JP, Sohl E, Brouwer-Brolsma EM, van Marwijk HW, et al. Effects of two-year vitamin B12 and folic acid supplementation on depressive symptoms and quality of life in older adults with elevated homocysteine concentrations: additional results from the B-PROOF study, an RCT. Nutrients 2016;8(11):E748. doi:10.3390/nu8110748.

[72] Okereke OI, Cook NR, Albert CM, Van Denburgh M, Buring JE, Manson JE. Effect of long-term supplementation with folic acid and $B$ vitamins on risk of depression in older women. Br J Psychiatry 2015;206(4):324-331. doi:10.1192/bjp.bp.114.148361.

[73] Loria-Kohen V, Gomez-Candela C, Palma-Milla S, Amador-Sastre B, Hernanz A, Bermejo LM. A pilot study of folic acid supplementation for improving homocysteine levels, cognitive and depressive status in eating disorders. Nutr Hosp 2013;28(3):807-815. doi:10.3305/ nh.2013.28.3.6335.

[74] Shuster JJ. Cochrane handbook for systematic reviews of interventions Version 5.1.0 [updated March 2011]. Higgins JPT, Green S, Editors. Research Synthesis Methods. 2011;2(2):126-130.

[75] American Psychiatric Association. Diagnostic and statistical manual of mental disorders DSM-IV-TR. Washington, DC: American Psychiatric Association, 2000. Available from: http://dsm.psychiatryonline. org/dsmPreviousEditions.

[76] World Health Organization. Periconceptional folic acid supplementation to prevent neural tube defects 2017 [updated 9 January 2017] Available from: http://www.who.int/elena/titles/folate_periconceptional/en/.

[77] Wald DS, Wald NJ, Morris JK, Law M. Folic acid, homocysteine, and cardiovascular disease: judging causality in the face of inconclusive trial evidence. BMJ 2006;333(7578):1114-1117. doi:10.1136/ bmj.39000.486701.68.

[78] van Wijngaarden JP, Doets EL, Szczecinska A, Souverein OW, Duffy ME, Dullemeijer C, et al. Vitamin B12, folate, homocysteine, and bone health in adults and elderly people: a systematic review with meta-analyses. J Nutr Metab 2013;2013:486186. doi:10.1155/2013/486186.

[79] Narayanan S, McConnell J, Little J, Sharp L, Piyathilake CJ, Powers H, et al. Associations between two common variants C677T and A1298C in the methylenetetrahydrofolate reductase gene and measures of folate metabolism and DNA stability (strand breaks, misincorporated uracil, and DNA methylation status) in human lymphocytes in vivo. Cancer Epidemiol Biomarkers Prev 2004;13(9):1436-1443.

[80] Jiang W, Xu J, Lu XJ, Sun Y. Association between MTHFR C677T polymorphism and depression: a meta-analysis in the Chinese population. Psychol Health Med 2016;21(6):675-685. doi:10.1080/135485 06.2015.1120327.

[81] Gabriela Nielsen M, Congiu C, Bortolomasi M, Bonvicini C, Bignotti $\mathrm{S}$, Abate $\mathrm{M}$, et al. MTHFR: Genetic variants, expression analysis and COMT interaction in major depressive disorder. J Affect Disord 2015;183:179-186. doi:10.1016/j.jad.2015.05.003.

[82] Smulders YM, Smith DE, Kok RM, Teerlink T, Swinkels DW, Stehouwer $\mathrm{CD}$, et al. Cellular folate vitamer distribution during and after correction of vitamin B12 deficiency: a case for the methylfolate trap. Br J Haematol 2006;132(5):623-629. doi:10.1111/j.13652141.2005.05913.x.

[83] Wang M, Li K, Zhao D, Li L. The association between maternal use of folic acid supplements during pregnancy and risk of autism spectrum disorders in children: a meta-analysis. Mol Autism 2017;8:51. doi:10.1186/s13229-017-0170-8. 
Explor Res Hypothesis Med

[84] Roffman JL, Petruzzi LJ, Tanner AS, Brown HE, Eryilmaz H, Ho NF, et al. Biochemical, physiological and clinical effects of I-methylfolate in schizophrenia: a randomized controlled trial. Mol Psychiatry 2017. doi:10.1038/mp.2017.41.

[85] Wang D, Zhai JX, Liu DW. Serum folate levels in schizophrenia: A meta-analysis. Psychiatry Res 2016;235:83-89. doi:10.1016/j.psychres.2015.11.045.

[86] Ghanizadeh A, Singh AB, Berk M, Torabi-Nami M. Homocysteine as a potential biomarker in bipolar disorders: a critical review and suggestions for improved studies. Expert Opin Ther Targets 2015;19(7):927939. doi:10.1517/14728222.2015.1019866.

[87] Mitchell ES, Conus N, Kaput J. B vitamin polymorphisms and behavior: evidence of associations with neurodevelopment, depression, schizophrenia, bipolar disorder and cognitive decline. Neurosci Biobehav Rev 2014;47:307-320. doi:10.1016/j.neubiorev.2014.08.006.

[88] Melnyk S, Pogribna M, Pogribny IP, Yi P, James SJ. Measurement of
Barnett H. et al: Folate supplementation and depression

plasma and intracellular S-adenosylmethionine and S-adenosylhomocysteine utilizing coulometric electrochemical detection: alterations with plasma homocysteine and pyridoxal 5'-phosphate concentrations. Clin Chem 2000;46(2):265-272.

[89] Reif A, Pfuhlmann B, Lesch KP. Homocysteinemia as well as methylenetetrahydrofolate reductase polymorphism are associated with affective psychoses. Prog Neuropsychopharmacol Biol Psychiatry 2005;29(7):1162-1168. doi:10.1016/j.pnpbp.2005.06.027.

[90] Liang S, Zhou Y, Wang H, Qian Y, Ma D, Tian W, et al. The effect of multiple single nucleotide polymorphisms in the folic acid pathway genes on homocysteine metabolism. Biomed Res Int 2014;2014:560183. doi:10.1155/2014/560183.

[91] Jones P, Beckett E, Yates Z, Veysey M, Lucock M. Converging evolutionary, environmental and clinical ideas on folate metabolism. Explor Res Hypothesis Med 2016;1(3):34-41. doi:10.14218/ ERHM.2016.00003b. 